\title{
Research on Key Factors Affecting Power Supply and Demand Trend Based on Complex Correlation
}

\author{
Dunnan Liu ${ }^{1}$, Rui $\mathrm{Ge}^{2}$, Pengfei $\mathrm{Li}^{1}{ }^{1,}$, Hua $\mathrm{Li}^{1}$, Shanzhe $\mathrm{Shi}^{3}$, Shilin $\mathrm{Li}^{3}$ and Jinshan Han ${ }^{1}$ \\ ${ }^{1}$ North China Electric Power University, Beijing, 102206, China \\ ${ }^{2}$ State Power Dispatch Control Center, Beijing, 100031, China \\ ${ }^{3}$ State Grid Electric Power co., LTD. In Hebei Province, Hebei, 050021, China
}

\begin{abstract}
The market behaviors of the supply and demand sides in the power market are the issues that market participants, operators and regulators are most concerned about. This article starts from the two dimensions of power generation market behavior and demand market behaviour, analyzes the impact of power transaction behavior on supply and demand trend changes, and then studies the function of big data technology in correlation analysis. The qualitative data is converted into quantitative data, and then gray rule analysis and correlation coefficient analysis are used to mine association rules. The results show that demand response is the key factor that affects the change of load trend.
\end{abstract}

\section{Introduction}

At present, there are many types of market members in the power market, and the market transaction behavior is diversified. This paper first analyzes the impact of generation-side transaction behavior and demand-side transaction behavior on supply and demand trends, and then studies based on data complex correlation analysis methods to identify the impact of supply and demand trends The key factor is to provide reference for the subsequent forecast of supply and demand trends and to promote the orderly development of the power market.

\section{The influence of electricity transaction on the trend of supply and demand}

Market behavior is not only the subjective strategy of market participants, but also the most concerned problem of market operators and regulators ${ }^{[1]}$. By analyzing various market behaviors of market members, we can analyze the impact on the change of supply and demand trend ${ }^{[1]}$.

This paper focuses on two aspects: supply side market behavior and demand side market behavior. The supply side market behavior mainly includes the ratio of low price, the ratio of up to limit price, the ratio of high price and the unit retention ratio on the generator side. The demand side market behavior mainly includes the demand response behavior and the ratio of declared electricity retention on the demand side.

\subsection{Supply side market behavior}

1) Proportion of quoted price
The ratio of quoted price to low price is the ratio of the number of units whose declared price is lower than a certain lower limit in a certain period of time to the number of all units. Generally, the lower limit of quoted price can be determined as $80 \%$ of the average fuel cost.

$$
L_{P}=\frac{q_{L}}{Q}
$$

In the formula:

$L_{p}-$ low price ratio;

$q_{L}$-Number of bidding units with quotation lower than a certain lower limit;

$Q-$ Number of units participating in bidding.

2) Limit rate of quotation

The limit rate of quoted price refers to the proportion of the number of units whose declared price reaches the upper limit in a certain period of time when the supply side power generation enterprises participate in the transaction.

$$
U_{P}=\frac{q_{U}}{Q}
$$

In the formula:

$U_{p} \longrightarrow$ Rate of unit quotation reaching the upper limit;

$q_{U}$ The number of units whose offer reaches the upper limit;

$Q-$ Number of units participating in bidding.

The higher the ratio of the quoted price to the upper limit, the tighter the supply-demand relationship in the market.

3) Proportion of quoted price

The ratio of quoted price to high price refers to the proportion of electricity that the supply side quoted price

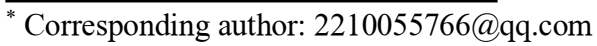


is close to the highest price in a certain period of time in the total declared electricity. The larger the proportion of quoted price is, the more willing the supply side power generation enterprises are to take greater risks to obtain higher profits.

$$
H_{P}=\frac{q_{H}}{Q}
$$

In the formula:

$H_{p} \longrightarrow$ Proportion of quoted price;

$q_{H}-$ The number of bidding units whose offer is close to the upper limit;

$Q-$ Number of units participating in bidding.

4) Unit retention ratio at supply side

The calculation formula of unit retention ratio on the supply side is as follows:

$$
\alpha=\frac{c_{i}-q_{i}}{c_{i}}
$$

In the formula:

$\alpha-$ unit retention ratio at the supply side;

$c_{i}$ Power generation capacity of generator group $i$ at the supply side;

$q_{i}$-Declaration of electricity quantity.

The unit retention ratio on the supply side is the main means for power generation enterprises to control market supply and demand. The higher the retention ratio is, the higher the control degree of suppliers over the supply is, which may lead to the tension of market supply and demand.

The closer the retention ratio is to 1 , the higher the extent to which the power generation enterprises on the supply side use market power to limit and raise the price, or the lower the attraction of the market to the power generation enterprises, indicating that the current market has a high profit making space and the market operation is likely to be unstable.

\subsection{Demand side market behavior}

\section{1) Demand response behavior}

Smart grid provides a two-way communication channel between power supply and load, strengthens the real-time interaction between power grid and users, and makes it feasible to adjust the demand side power consumption. It mainly guides the users to adjust the controllable load resources through the electricity price policy or incentive policy, realizes the interactive response dispatching of flexible load, realizes the optimal adjustment of load, and then changes the demand side power consumption curve to affect the market supply and demand.

2)Retention ratio of declared electricity on demand side

In the market environment, the demand side has the opportunity to reduce the price by holding the declared electricity, so as to obtain a lower price. This holding behavior is often not easy to be found, which will seriously damage the stable operation of the power market. The demand side can try to reduce the market clearing price by quoting a low price, so that its purchasing power can get a lower price. Reduce the declared power to retain the power, reduce the power on the demand side, and affect the overall supply and demand trend of the market.

\section{Complex correlation analysis technology based on big data}

\subsection{Grey relational analysis}

The general abstract system contains many influencing factors, and the result of the combination of multiple factors determines the development trend of the system ${ }^{[2]}$. The basic idea of the gray correlation analysis method is to judge whether the connections are close according to the similarity of the geometric shapes of the sequence curves. The closer the curves are, the greater the degree of correlation between the corresponding sequences, and the smaller the opposite.

\section{(1) Grey correlation}

Let $X_{0}=\left(x_{0}(1), x_{0}(2), \ldots, x_{0}(n)\right)$ be the feature series of the system and

$$
X_{i}=\left(x_{i}(1), x_{i}(2), \ldots, x_{i}(n)\right)(i=1,2, \ldots m)
$$

Is the system related factor sequence, where $n$ is the length of the historical sequence, and $m$ is the number of related factors. Given a real number $\gamma\left(x_{0}(k), x_{i}(k)\right) \quad, \quad$ if the real number $\mathrm{\gamma}\left(X_{0}, X_{i}\right)=\frac{1}{n} \sum_{k=1}^{n} \gamma\left(x_{0}(k), x_{i}(k)\right)$ satisfy:

1) Normative: $0 \leq \gamma\left(x_{0}(k), x_{i}(k)\right) \leq 1$, means that no factor in the system can be strictly uncorrelated, $\quad \mathrm{\gamma}\left(x_{0}(k), x_{i}(k)\right)=1$ means fully correlated, $\gamma\left(x_{0}(k), x_{i}(k)\right)=0$ means completely unrelated.

2) Even symmetry: When two sets of sequences $\gamma\left(X_{i}, X_{j}\right)=\gamma\left(X_{j}, X_{i}\right), \quad \mathrm{j} \neq \mathrm{i}$, which indicates that the comparison between the two sequences is symmetrical.

3) Holistic: When the sequence is larger than three groups (including three groups), $\gamma\left(X_{i}, X_{j}\right) \neq \gamma\left(X_{j}, X_{i}\right)$, $\mathrm{j} \neq \mathrm{i}$, indicates that when the association comparison is performed in a certain environment, the choice of different reference sequences is due to the different environment. The comparison result is not necessarily consistent with the principle of symmetry.

4) Proximity : If $\left|x_{0}(k)-x_{i}(k)\right|$ is smaller, $\gamma\left(x_{0}(k), x_{i}(k)\right)$ is larger. Then $\gamma\left(X_{0}, X_{i}\right)$ is called the gray correlation degree of $X_{i}$ to $X_{o}$, and the above four are called the four axioms of gray correlation.

A commonly used definition of gray correlation is given below:

Assume

$X_{o}=\left(x_{o}(1), x_{o}(2), \ldots, x_{o}(n)\right), X_{i}=\left(x_{i}(1), x_{i}(2), \ldots, x_{i}(n)\right)$ that the correlation coefficient is defined as: 


$$
\begin{aligned}
& \gamma\left(x_{0}(\mathrm{k}), x_{i}(\mathrm{k})\right)= \\
& \frac{\min _{i} \min _{k}\left|x_{0}(\mathrm{k})-x_{i}(\mathrm{k})\right|+\rho \max _{i} \max _{k}\left|x_{0}(\mathrm{k})-x_{i}(\mathrm{k})\right|}{\left|x_{0}(\mathrm{k})-x_{i}(\mathrm{k})\right|+\rho \max _{i} \max _{k}\left|x_{0}(\mathrm{k})-x_{i}(\mathrm{k})\right|}
\end{aligned}
$$

In the formula, $\left|x_{o}(k)-x_{i}(k)\right|$ is the absolute error of the k-th point of; $\min _{i} \min _{k}\left|x_{o}(k)-x_{i}(k)\right|$ is the minimum difference between two levels; $\max _{i} \max _{k}\left|x_{o}(k)-x_{i}(k)\right|$ is the maximum difference between two levels; $\rho$ is called the resolution $(0<\rho<1)$, and generally takes $\rho=0.5^{[3]}$.

\subsection{Calculation steps of gray correlation}

1) Find the initial image (or mean image) of each series,

$X_{i}^{\prime}=X_{i} / x_{i}(1)=\left(x_{i}^{\prime}(1), x_{i}^{\prime}(2), \ldots, x_{i}^{\prime}(n)\right) . i=$ $0,1,2, \ldots, m$

2) Calculate the difference sequence,

$$
\begin{array}{r}
\triangle_{i}(k)=\left|x_{0}^{\prime}(k)-x_{i}^{\prime}(k)\right| \\
\triangle_{i}=\left(\triangle_{i}(1), \triangle_{i}(2), \ldots, \triangle_{i}(n)\right)
\end{array}
$$

$i=0,1,2, \ldots, m$

3) Find the maximum difference and minimum difference between two levels

$$
\begin{gathered}
M=\max _{i} \max _{k} \Delta_{i}(k) \\
m=\min _{i} \min _{k} \Delta_{i}(k)
\end{gathered}
$$

4) Find the correlation coefficient

$$
\gamma_{0 i}(k)=\frac{m+\rho M}{\Delta_{i}(k)+\rho M}, \rho \in(0,1)
$$

$k=1,2, \ldots, n ; i=1,2, \ldots, m$

5) Calculate relevance

$$
\gamma_{0 i}=\frac{1}{n} \sum_{k=1}^{n} \gamma_{0 i}(k) ; \quad i=1,2, \ldots, m
$$

In order to reduce the influence of the correlation coefficient of the data series before calculating the gray

Table 2. Similarity identification results of different indicators

\begin{tabular}{l|l|c|c|c}
\hline \multicolumn{2}{l}{ Market behavior } & \multicolumn{2}{c|}{$\begin{array}{c}\text { Correlation degree } \\
\text { identification }\end{array}$} & outcome \\
\hline $\begin{array}{l}\text { Generation side market } \\
\text { behavior }\end{array}$ & $\begin{array}{l}\text { Proportion of } \\
\text { quoted price }\end{array}$ & 0.7426 & 0.5863 & NO \\
\cline { 2 - 6 } & $\begin{array}{l}\text { Limit rate of } \\
\text { quotation }\end{array}$ & 0.6588 & 0.4562 & NO \\
\cline { 2 - 5 } & $\begin{array}{l}\text { Proportion of } \\
\text { quoted price }\end{array}$ & 0.7084 & 0.4428 & NO \\
\cline { 2 - 5 } & $\begin{array}{l}\text { Unit } \\
\text { retention } \\
\text { ratio at } \\
\text { generator } \\
\text { side }\end{array}$ & 0.8751 & 0.3562 & NO \\
\hline $\begin{array}{l}\text { Demand side market } \\
\text { behavior }\end{array}$ & $\begin{array}{l}\text { Demand } \\
\text { response } \\
\text { behavior }\end{array}$ & 0.9299 & 0.9480 & YES \\
\cline { 2 - 5 } & $\begin{array}{l}\text { Retention } \\
\text { ratio of } \\
\text { declared } \\
\text { electricity on } \\
\text { demand side }\end{array}$ & 0.5036 & 0.4036 & NO \\
\hline
\end{tabular}

correlation degree, the data series need to be standardized. In this study, the standard normalization is used, that:

$$
x_{i}^{(1)}(t)=\frac{x_{i}(t)-\overline{x_{i}}}{s}
$$

Where $\bar{x}_{i}$ is the mean of the series and $s$ is the standard deviation, that is $\mathbf{s}=\sqrt{\frac{1}{n-1} \sum_{t=1}^{n}\left(x_{i}(t)-\overline{x_{l}}\right)^{2}}$, $i$ is the data serial number ${ }^{[4]}$.

\subsection{Judgment criteria for grey correlation}

Table 1. Criteria for grey correlation

\begin{tabular}{l|l}
\hline $\begin{array}{l}\text { Grey } \\
\text { correlation }\end{array}$ & Strong relevance \\
\hline $0.8-1.0$ & More relevant \\
\hline $0.5-0.8$ & Moderate relevance \\
\hline $0-0.5$ & $\begin{array}{l}\text { Weakly related or } \\
\text { unrelated }\end{array}$ \\
\hline
\end{tabular}

\section{Analysis of key influencing factors based on complex association of big data}

By using the grey correlation analysis technology, this paper studies and calculates the correlation degree between various market behaviors and market supply and demand trend, and obtains the key factors influencing supply and demand trend, which lays the foundation for the construction of supply and demand trend prediction method. Through the calculation of correlation degree and correlation coefficient, the impact of market behavior and supply and demand trend is obtained, as shown in the following table ${ }^{[5]}$ : 
The above table gives the descriptive statistics of different market behaviors, including grey correlation degree and correlation coefficient. Obviously, the demand response behavior has a great influence on the supply and demand trend.

Results analysis: the influencing factors such as the ratio of low price, the ratio of up to limit price, the ratio of high price, the ratio of unit retention on the generator side, the ratio of electricity retention on the demand side are mainly the part of market behavior of a single market entity. In the key period of the current market-oriented reform of electric power, with the continuous promotion of the reform of the electricity selling side, the market competition is relatively sufficient, the market supervision system is gradually improved, and the partial unfair competition behavior of a single market subject is not enough to affect the competition trend of the whole electric power market. In the new-type power market of source and load interaction, through TOU (time of use), RTP (real time pricing), CPP (critical peak pricing) and other price based programs, DLC (direct load control), IL (intermittent load), DSB (demand side binding) and other intensive based programs Programs and other measures mobilize a large number of users on the demand side to complete the flexible load optimization adjustment, change the demand curve on the demand side, and then affect the supply and demand trend prediction of the power market.

\section{Analysis of Examples}

This project uses industrial user load data in a certain area as an example to verify the effectiveness of the method. In the example analysis, it is assumed that most of the user's production costs come from the power purchase cost, and its production curve can be changed as the power purchase cost decreases. This example does not consider other factors that affect production costs, such as labor costs.Before the implementation of peak and valley electricity prices, the electricity price in this area was 0.4 yuan $/ \mathrm{Kw} \cdot \mathrm{h}$. Peak and valley periods were divided according to load data. Peak periods were: 08: 00-12: 00 and 13: 00-18: 00, and flat periods were: 120 : 00-13: 00 and 18: $00-20: 00$, the valley period is $20: 00-$ 08: 00. The following table shows the demand-side forecast data and supply-side forecast data before the implementation of peak-valley electricity prices.

Table 3. Demand-side forecast data and supply-side forecast data table before implementation of peak-valley electricity prices

\begin{tabular}{c|c|c|c|c|c}
\hline Period & $\begin{array}{c}\text { Demand-side forecast data } \\
\text { before implementation of } \\
\text { peak-valley electricity prices } \\
(10,000 \mathrm{~kW})\end{array}$ & $\begin{array}{c}\text { Supply-side } \\
\text { forecast data } \\
(10,000 \mathrm{~kW})\end{array}$ & Period & $\begin{array}{c}\text { Demand-side forecast data } \\
\text { before implementation of } \\
\text { peak-valley electricity prices } \\
(10,000 \mathrm{~kW})\end{array}$ & $\begin{array}{c}\text { Supply-side } \\
\text { forecast data } \\
(10,000 \mathrm{~kW})\end{array}$ \\
\hline 1 & 10 & 35 & 13 & 20 & 28 \\
\hline 2 & 10 & 33 & 14 & 37 & 27 \\
\hline 3 & 10.5 & 35 & 15 & 38.1 & 26 \\
\hline 4 & 10.5 & 30 & 16 & 35 & 25 \\
\hline 5 & 11.4 & 27 & 17 & 35 & 25 \\
\hline 6 & 12 & 26 & 18 & 26.3 & 25 \\
\hline 7 & 10 & 14 & 19 & 27.2 & 35 \\
\hline 8 & 35 & 20 & 20 & 20 & 35 \\
\hline 9 & 37 & 25 & 21 & 18 & 29 \\
\hline 10 & 39.2 & 25 & 22 & 18 & 37 \\
\hline 11 & 38.5 & 26 & 23 & 15.1 & 40 \\
\hline
\end{tabular}

The demand-side forecast data and supply-side forecast data before the implementation of peak-valley electricity prices are shown in the following figure:

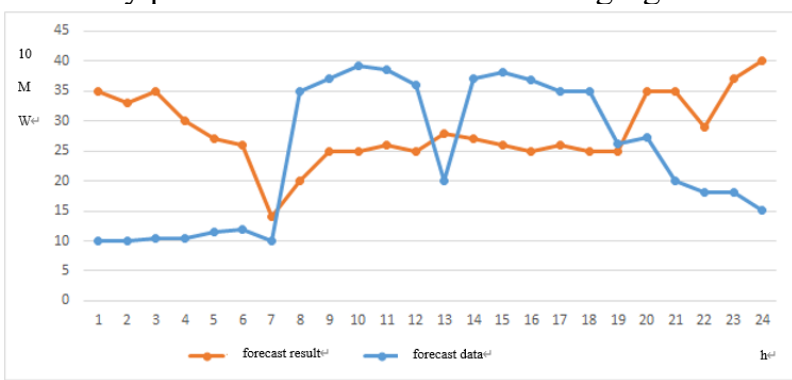

Fig. 1. Demand-side forecast data and supply-side forecast data before peak-valley electricity prices are implemented

According to the analysis of the local economic level, the expected rate of return for the electricity tariff of the power supply side agent is $1 \%-2 \%$. In order to ensure the stability of the power grid, at the same time, the maximum peak-to-valley difference after optimization is taken into account $200,000 \mathrm{Kw}$. According to the analysis of this user, the maximum load transfer rate from peak to valley is $15 \%$, the maximum load transfer from peak to valley is $20 \%$, and the maximum load transfer from peak to valley is $10 \%$.

\section{Conclusion}

This article starts from the two dimensions of power generation market behavior and demand market behavior, analyzes the impact of power transaction behavior on supply and demand trend changes, and then studies the function of big data technology in correlation analysis. The qualitative data is transformed into quantitative data, and then the gray rule analysis and correlation 
coefficient analysis are used to mine the association rules. The results show that demand response is the key factor that affects the change of load trend.

\section{Acknowledgements}

Science and Technology Project of State Grid Corporation of China, Integrated Operation Control Strategy of Cross District Whole Network Adapting to the Development of New Energy , Number: SGTYHT/16-JS-198.

\section{References}

1. Q.F. Chen, M.C. Xia, M. Guo, et al. Power Supply, Short-term load forecasting method of electric heating district based on data feature mining, 36, 48 (2019)

2. F.S. Wen, Q. Wang, M. Liu, S. Yi. Journal of Electric Power Systems and Automation, European Power Market Evaluation System, 21,23 (2009)

3. T. Li,S.Y. Wang. Industrial Technology \& Economy, Research on China's electricity market transaction evaluation system based on gray correlation and fuzzy comprehensive evaluation method,37, 130(2018)

4. Y.L. Wang, M.K. Wu,Z.Q. Zhou,H.Y. Ma. Power System Technology, Quantitative analysis model of power load influencing factors based on improved gray correlation ,6,1772(2017)

5. X.F. Wang,Y.P. Xiao, X.L. Wang. Chinese Journal of Electrical Engineering, Research and Analysis of Power Supply and Demand Interaction in New Situation ,29,5018(2014)

6. W. Liu.Beijing Jiaotong University, Research on early warning of power supply and demand and load optimization in Beijing(2015) 